\title{
Design and Performance Analysis of a Modified Vacuum Single Basin Solar Still
}

\author{
Moses Koilraj Gnanadason ${ }^{1 *}$, Palanisamy Senthil Kumar², Gopal Sivaraman ${ }^{3}$, \\ Joseph Ebenezer Samuel Daniel ${ }^{4}$
}

\begin{abstract}
${ }^{1}$ Research Scholar, PRIST University, Thanjavur, India; ${ }^{2}$ Mechanical Engineering Department, KSR College of Engineering, Tiruchengode, India; ${ }^{3}$ Faculty of Mechanical Engineering, PAAVAI Group of Institutions, Pachel, India; ${ }^{4}$ Faculty of Mechanical Engineering, JACSI College of Engineering, Nazareth, India.

Email: koiljemil@yahoo.co.in
\end{abstract}

Received July $26^{\text {th }}$, 2011; revised September $23^{\text {rd }}$, 2011; accepted September $30^{\text {th }}$, 2011.

\begin{abstract}
Water is essential to life. The origin and continuation of mankind is based on water. The supply of drinking water is an important problem for the developing countries. Among the non-conventional methods to desalinate brackish water or seawater, is solar distillation. The solar still is the most economical way to accomplish this objective. Tamilnadu lies in the high solar radiation band and the vast solar potential can be utilized to convert saline water to potable water. The sun's energy heats water to the point of evaporation. When water evaporates, water vapour rises leaving the impurities like salts, heavy metals and condensate on the underside of the glass cover. Sunlight has the advantage of zero fuel cost but it requires more space and generally more equipment. Solar distillation has low yield, but safe and pure supplies of water in remote areas. In this context, the design modification of a single basin solar still has been discussed to improve the solar still performance through increasing the production rate of distilled water. The attempts are also made to increase the productivity of water by using different absorbing materials, depths of water, heat storage medium and also by providing low pressure inside the still basin. They greatly improve the rate of evaporation and hence the rate of condensation on the cooler surface. The theoretical results agree well with the experimental ones.
\end{abstract}

Keywords: Solar Still, Design Modifications, Thermal Performance, Heat Storage

\section{Introduction}

Clean water is a basic human necessity and without water life will be impossible. The provision of fresh water is becoming an increasingly important issue in many areas of the world. The increasing world population growth together with increasing industrial and agricultural activities all over the world contributes to the depletion and pollution of fresh water resources. Worldwide drought and desertification are expected to increase the problem [1]. The importance of supplying potable water can hardly be overstressed. Water is an abundant natural resource that covers three quarters of the earth's surface. However, only about $3 \%$ of all water sources is potable. Less than $1 \%$ fresh water is within human reach and the rest is ice. Even this small fraction (ground water, lakes and rivers) is believed to be adequate to support life and vegetation on the earth. $30 \%$ of all fresh water is underground, most of it in deep, hard-to-reach aquifers. Lakes and rivers together contain just a little more than $0.25 \%$ of all fresh water; lakes contain most of it [2]. Remote and arid regions depend on underground water for drinking. In arid areas potable water is very scarce and the establishment of a human habitat in these areas strongly depends on how such water can be made available. In some instances, the salinity is probably too high for water to be considered as fresh drinking water; instead it is called brackish water. The salinity of brackish water varies with locations. In such cases, fresh water has to be either transported for long distances or connected with an expensive distribution water network at extremely high cost for a small population. Nowadays pollution in rivers and lakes by industrial effluents and sewage disposal has resulted in scarcity of fresh water in many big towns and cities around the world [3].

One of the most important properties in such analysis is salinity. Salinity is usually expressed in parts per million (ppm). The excessive brackishness causes problems of taste, stomach problems and laxative effects. According to World Health Organization (WHO), the permissi- 
ble limit of salinity in water is $500 \mathrm{ppm}$ [4].

The rapid increasing need for energy and environmental concerns has focused much attention on renewable energy resources. The use of solar energy is more economical than the use of fossil fuel in remote areas having low population densities, low rain fall and abundant available solar energy. A simple solar still can easily produce the water needed for drinking and cooking for households without access to potable water. Also distilled water can be used for industrial purpose as it is cleaner. It is a simple technology which can be operated by non-skilled workers. Also due to the low maintenance requirement, it can be used anywhere with lesser number of problems. In solar desalination process, the productivity of the solar still is very less in the range of 2 - 5 litres $/ \mathrm{m}^{2} /$ day only compared to other conventional desalination systems. The problem is to enhance the amount of water produced [5].

Various parameters affect both efficiency and productivity of the still. The distilled water production rate can be increased by varying design of the solar still, depths of water, salt concentration, location and different absorbing materials and evaporative techniques. In this context, distilled water evaporation rate is enhanced by using solar still made up of Copper sheet instead of Cast Iron. The attempts are also made to increase the productivity of water by painting black coating inside the basin and placing high solar thermal energy storage materials like small pebbles inside the water to retain heat.

\section{Solar Still}

As the available fresh water is fixed on earth and its demand is increasing day by day due to increasing population and the rapid increase of industry, hence there is an essential and earnest need to get fresh water from the saline/brackish water present on or inside the earth. This process of getting fresh water from saline/brackish water can be done easily and economically by desalination. Owing to the diffuse nature of solar energy, the main problems with the use of solar thermal energy in largescale desalination plants are the relatively low productivity rate, the low thermal efficiency and the considerable land area required. Apart from the cost implications, there are environmental concerns with regard to the burning of fossil fuels [6]. Solar energy can directly or indirectly be harnessed for desalination. The solar stills are simple and have no moving parts.

\subsection{Priciple of Desalination}

Desalination is one of the most important methods of getting potable water from brackish and sea water by using the free energy supply from the sun. In nature, solar desalination produces rain when solar radiation is absorbed by the sea and causes water to evaporate. The evaporated water rises above the earth's surface and is moved by the wind. Once this vapour cools down to its dew point, condensation occurs, and the fresh water comes down as rain as shown in Figure 1. The same principle is used in all manmade distillation systems using alternative sources of heating and cooling. Working of solar still is based on the simple scientific principle of evaporation and condensation. There are several types of solar stills, the simplest of which is the single basin still. But the yield of this is low and falls in the range of 3 4litres per day per square metre [7]. Different still designs have been used in different regions globally, where high quality drinking water supplies are scarce and the solar option is viable. The operation of solar still is very simple and no special skill is required for its operation and maintenance.

\subsection{Working of Solar Still}

In conventional basin type solar still, the still consists of a shallow airtight basin lined with a black, impervious material, which contains brackish or saline water as shown in Figure 2. Solar radiation received at the surface is absorbed effectively by the black surface and heat is transferred to the water in the basin. Temperature of the water increases and it increases the rate of evaporation. A sloping transparent cover is provided at the top. Water vapour produced by evaporation rises upward and condenses on the inner surface of the glass cover which is

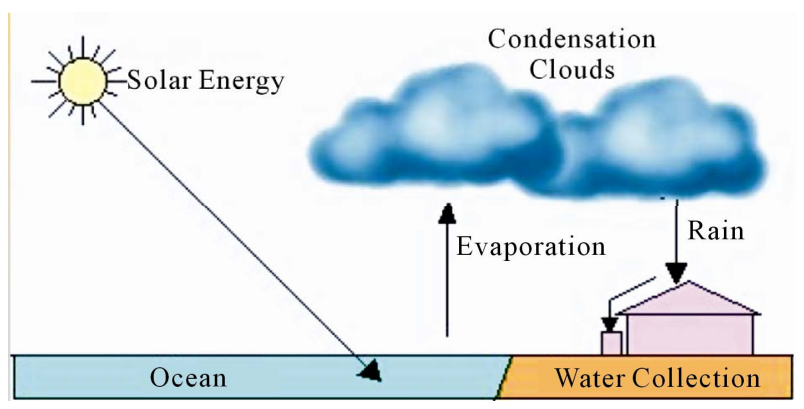

Figure 1. Priciple of desalination.

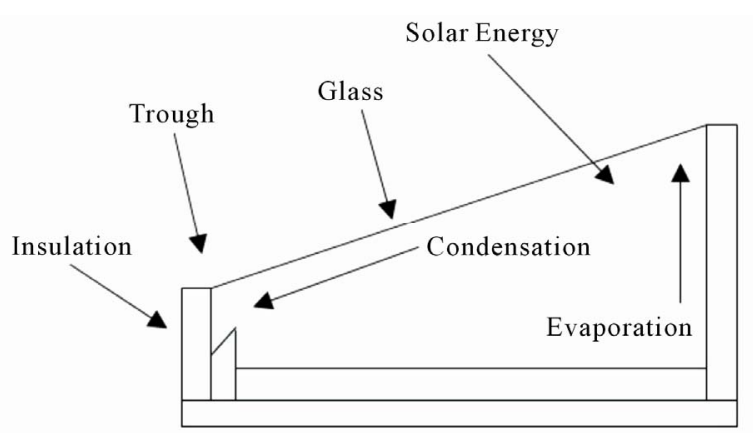

Figure 2. Skeleton of solar still. 
relatively cold. Condensed water vapour trickles down into the trough and from there it is collected in the storage container as distilled water.

The distilled water from a solar still has excellent taste when compared with commercially distilled water since the water is not boiled (which lowers $\mathrm{pH}$ ). This allows for natural $\mathrm{pH}$ buffering that produces excellent taste as compared to steam distillation. Solar stills can easily provide enough water for the drinking and cooking needs of the family. They are made of quality materials designed to stand up to the harsh conditions produced by water and sunlight. Water may be added through the still's supply fill port. Purified drinking water is collected from the output collection port as distillate.

\section{Experimental Setup}

\subsection{Solar Still Made Up of Copper}

It should be noted that before considering the application of any desalination method, water conservation measures should be considered first. In the recent years, a number of models for solar distillation have been presented in literature by various investigators. Mainly, they have single and double slope solar collectors.

As shown in Figure 3, the solar still consists of a shallow triangular basin made up of Copper sheet instead of G.I Sheet. As Copper has higher thermal conductivity of $395 \mathrm{~W} / \mathrm{mK}$ comparatively higher than Iron, the rate of heat transfer to water in the still is more. The bottom of the basin is usually painted black to absorb the sun's heat which in turn increases the evaporation rate. The top of

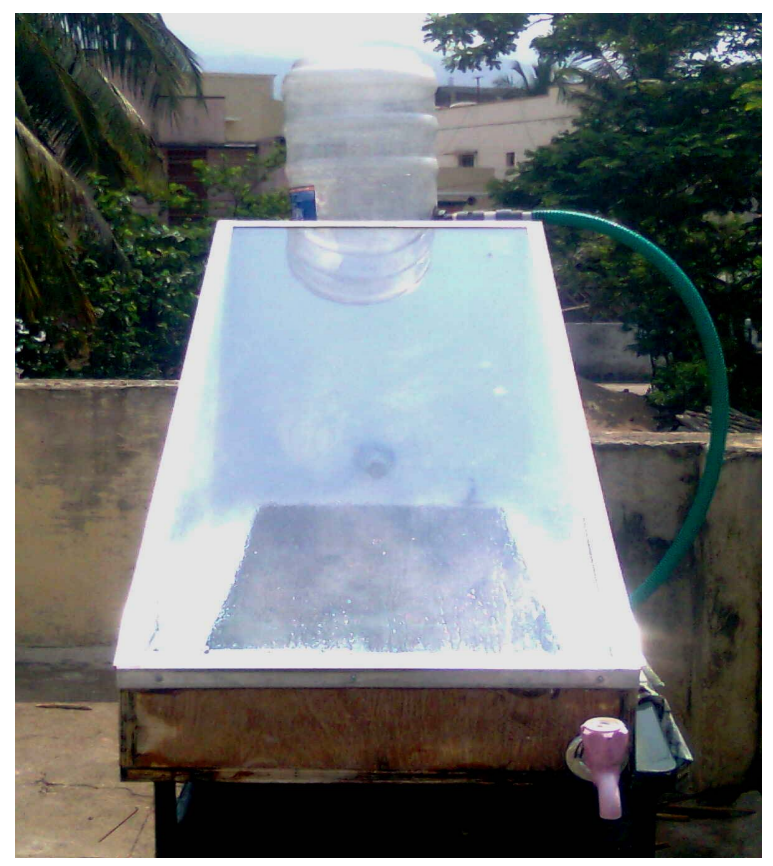

Figure 3. Experimental setup. the basin is covered with a glass of $4 \mathrm{~mm}$ thick. Tilted fixed $32^{\circ}$ so as to allow maximum transmission of solar radiation and helps the condensed vapour to trickle down into the trough, built in channel in the still basin. The edge of the glass is sealed with a tar tape so as to make the basin airtight. The entire assembly is placed on a stand structure made up of M.S angles. The outlet is connected to a storage container through a pipe. Provision is made to change water in the stills. The still is filled with the brackish water in a thin layer.

The basin liner is made of a copper sheet of $900 \times 400$ $\times 50 \mathrm{~mm}$ and $1.5 \mathrm{~mm}$ thickness. The copper sheet is painted by red-lead primer then by matt-type black paint. There are certain specifications needed for the glass cover used in the still. They have a minimum amount of heat absorption, minimum amount of reflection for solar radiation energy, maximum transmittance for solar radiation energy, and high thermal resistance for heat loss from the basin to the ambient.

Glass cover has been sealed with silicon rubber which plays an important role to promote efficient operation as it can accommodate the expansion and contraction between dissimilar materials. A thermo cool of $2.5 \mathrm{~cm}$ thickness with thermal conductivity of $0.045 \mathrm{~W} / \mathrm{mK}$ is used as insulating material to reduce the heat losses from the bottom and the side walls of the solar still. A small feeding tank is installed in the system as a constant head tank which is used to maintain the level of water inside the still basin constant by a floating ball. The outer box is made up of plywood.

Figure 4 and Figure 5 show the setup with and without heat storage medium (stones) of the still basin. To absorb and retain the heat obtained by solar radiation, heat absorbing materials like stones are placed inside the still. Various aspects such as temperature and productivity are to be measured once every hour. And also the percentage of salt concentration is added to water like $0 \%, 10 \%$, and $20 \%$ depending upon the water depth in the still basin. For different depths of water levels of ba$\sin 1 \mathrm{~cm}, 3 \mathrm{~cm}$ and $5 \mathrm{~cm}$, readings are taken to find the variation in yield.

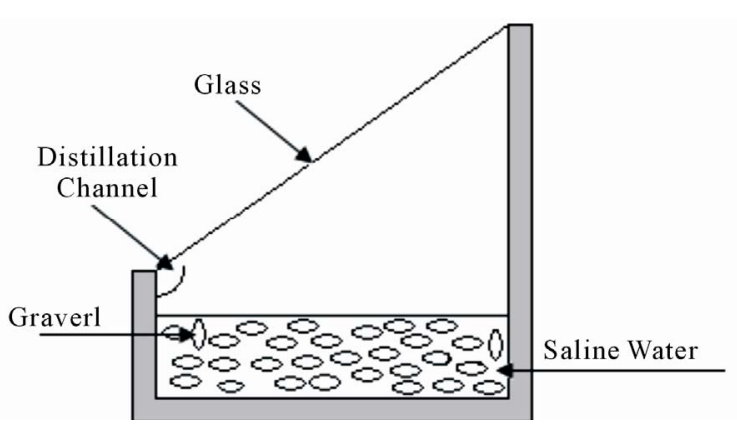

Figure 4. Still with heat storage. 


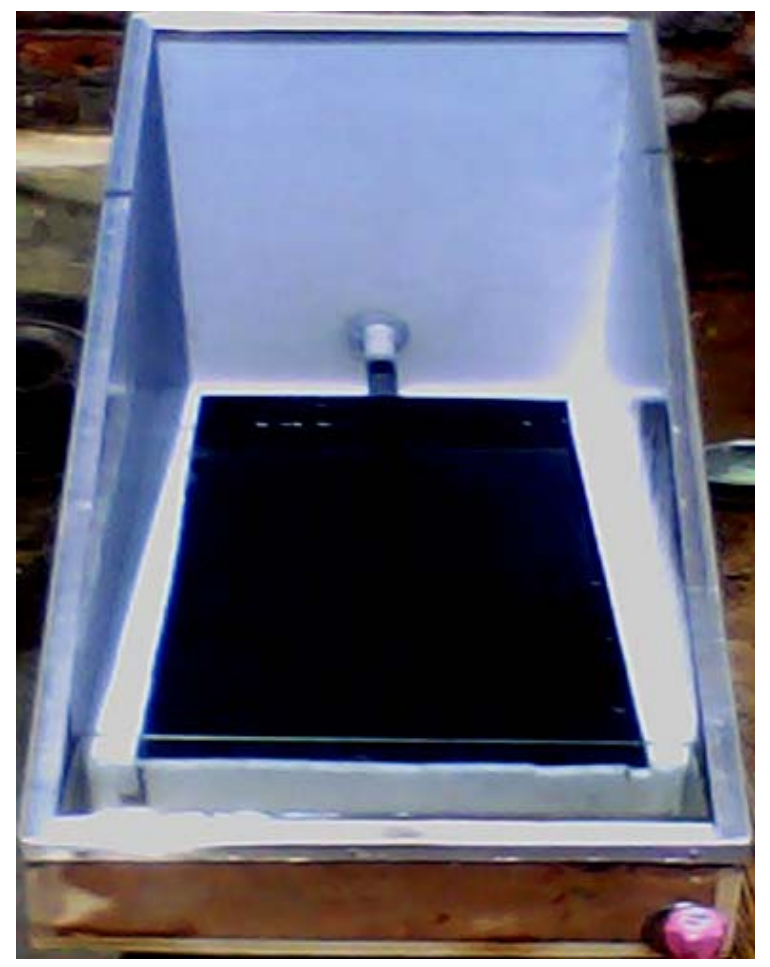

Figure 5. Still without heat storage.

The evaporation rate of the water in the solar still is directly proportional to the exposure area of water in the still, absorber area and temperature of water in the basin. Pebble is one of the highest solar thermal energy storage materials as it has high sensible heat. A pebble of uniform diameter $10 \mathrm{~mm}$ is used. Addition of pebbles in the basin surface increases the water temperature thereby increasing the evaporation rate. The area productivity of the solar still increases with the increase in absorber area.

\subsection{Specifications}

The materials selection and design specification of the solar still is shown in Table 1. The material used for still basin is Copper sheet because of its higher thermal conductivity. To transmit the maximum solar radiation to the basin water, Glass is used as top cover. Thermo cool is used as an insulating material to reduce heat transfer rate and also it is economical. Plywood is used as outer cover to keep the still basin inside.

\subsection{Measurements}

The solar still made up of Copper, inside bottom black colour coated is operated from 6:00 am to 6:00 pm during the months of April and May 2011. The measurements of the temperatures, solar radiation intensity, and the production of distilled water are taken hourly to study the effect of each parameter on the still productivity. In this study various operating conditions have been exam-
Table 1. Specification.

\begin{tabular}{cccc}
\hline $\begin{array}{c}\text { Parts } \\
\text { name }\end{array}$ & Material & Size & $\begin{array}{c}\text { Purpose of } \\
\text { selection }\end{array}$ \\
\hline $\begin{array}{c}\text { Still outer } \\
\text { box }\end{array}$ & plywood & $\begin{array}{c}1130 \times 500 \times 650 \\
\mathrm{~mm}\end{array}$ & $\begin{array}{c}\text { Low cost and } \\
\text { stability }\end{array}$ \\
$\begin{array}{c}\text { Still } \\
\text { Basin }\end{array}$ & $\begin{array}{c}\text { Copper } \\
\text { sheet }\end{array}$ & $\begin{array}{c}400 \times 900 \times 60 \mathrm{~mm} \\
\text { Thickness } 1.5 \mathrm{~mm}\end{array}$ & $\begin{array}{c}\text { High heat } \\
\text { conductivity }\end{array}$ \\
$\begin{array}{c}\text { Top Glass } \\
\text { Cover }\end{array}$ & Glass & $1230 \times 500 \times 4 \mathrm{~mm}$ & $\begin{array}{c}\text { High } \\
\text { transmitivity }\end{array}$ \\
$\begin{array}{c}\text { Thermo } \\
\text { cool }\end{array}$ & $\begin{array}{c}\text { Thermo } \\
\text { cool }\end{array}$ & $25 \mathrm{~mm}$ thick & $\begin{array}{c}\text { Insulation, } \\
\text { low cost }\end{array}$ \\
\hline
\end{tabular}

ined such as; different water depth, insulation thickness, ambient temperature and salt concentration with and without heat storage medium stones inside the till. The variables such as $T_{g}$ in, $T_{g}$ out, $T_{a}, T_{w}, T_{p}$ and productivity are measured hourly.

The total productivity and solar Intensity for each day are also measured. Also, different experimental tests are carried out at different ambient conditions. From about 2 $\mathrm{pm}$, water temperature decreases due to the loss from the solar still which becomes larger than the absorbed solar radiation. It can be noted that the basin temperature gets closer to the water temperature because of the continuous contact between them which leads to heat equilibrium.

As the glass temperature is much lower than the vapour temperature, it causes condensation of vapour on the glass. In the early hours of the morning (8 - $9 \mathrm{am}$ ), the glass temperature is higher than the water and vapour temperatures causing small productivity due to the small energy absorbed by the water at these times. There is increase in the solar intensity in the early morning until it reaches the maximum at around 12 to $2 \mathrm{pm}$, and then it decreases in the late afternoon. The solar intensity has an important effect on the solar still productivity. As the solar intensity increases, the productivity increases due to the increase in heat gain for water vaporization inside the still.

The productivity rate varies as time passes from the early morning until late afternoon. In the morning, the temperature of water is low; therefore it needs high energy to change its phase from saturated liquid to saturated vapour phase. The results show that temperature and required heat are inversely proportional. In the early afternoon the temperature of water reaches the maximum so it needs less heat to vaporize, and vice versa in the late afternoon.

The same measurement process is repeated for various parameters to find out the enhanced performance of the copper still by using heat storage medium like small pebbles inside the still basin which helps to retain heat inside the still. Pebble is one of the highest solar thermal energy 
storage materials as it has high sensible heat. Addition of pebbles in the basin surface increases the water temperature and thereby increasing the evaporation rate. The productivity is significantly increased by black painting and placing stones inside the still.

\section{Modified Vacuum Solar Still}

We all know that boiling takes place when the ambient temperature equals that of the vapour pressure of the liquid. This means that we can increase the rate of evaporation by reducing the pressure of the still. This will ensure higher rates of evaporation even at low temperatures. As stated already, we need to reduce the working pressure inside the distiller to increase the rate of evaporation at lower temperatures and hence increase in efficiency. One more additional feature in this still that we are proposing is that it would use the latent heat which is released during condensation to heat up the water at lower temperature. This is achieved by using an innovative staged still design as shown in Figure 6.

We are looking at the operating conditions of about $60^{\circ} \mathrm{C}$ to ensure low heat transfer losses. At this temperature the vapour pressure of water is $20 \mathrm{KPa}$. So we need to operate the pump to reduce the pressure to this value and then leave it in the sun for distillation. This will ensure boiling of water inside the distiller as soon as the temperature reaches $60^{\circ} \mathrm{C}$, which is pretty low and easily achievable by using simple designs. In the design we have incorporated a simple vacuum pump to reduce pressure inside the distillation chamber which will be operated intermittently to maintain the vacuum constantly. At that time a separate condensation chamber is used to condense the vapour leaving through the vacuum pump. The same measurement process is repeated for various parameters to find out the enhanced performance of the vacuum still with and without heat storage pebbles and compare the performance of them. Addition of pebbles in the basin surface increases the water temperature and

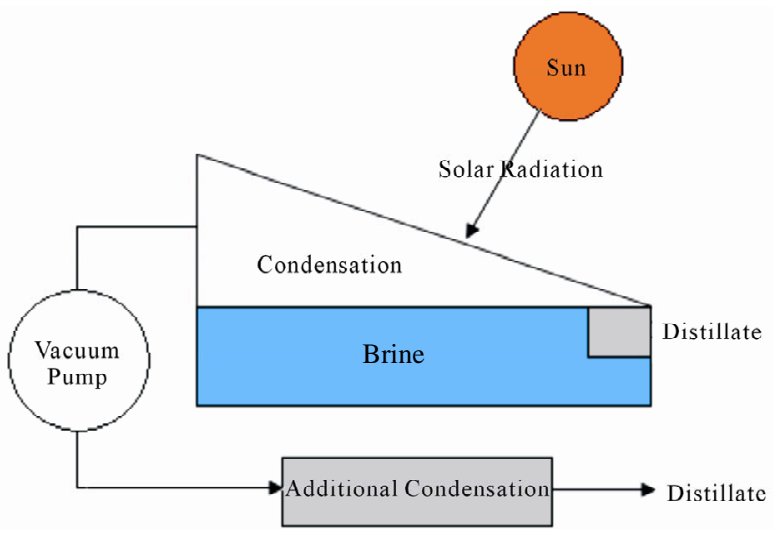

Figure 6. Vacuum solar still setup. thereby increasing the evaporation rate of the modified vacuum still.

\section{Theoretical Analysis}

The energy received by the saline water in the still (from the sun and base) is equal to the summation of energy lost by convective heat transfer between water and glass, radiative heat transfer between water and glass, evaporative heat transfer between water and glass, and energy gained by the saline water:

$$
\begin{aligned}
& I(t) a_{w} A_{w}+Q_{c} b-w \\
& =Q_{c} w-g+Q_{r} w-g+Q_{e} w-g+m_{w} c_{p w} \mathrm{~d} T / \mathrm{d} t_{F}
\end{aligned}
$$

Following Dunkle (1961), the rate energy lost from water surface by evaporation per $\mathrm{m}^{2}$ is given by

$$
\begin{gathered}
q_{e w}=0.0163 h_{c w}\left(p_{w}-p_{g}\right) \\
N u=\frac{h_{c w} d}{k}=C \cdot(G r \cdot \operatorname{Pr})^{n}
\end{gathered}
$$

The hourly distillate output per $\mathrm{m}^{2}$ from distiller unit is given by

$$
\begin{aligned}
m_{w}= & \frac{q_{e w}}{L} X 3600 \\
= & 0.0163\left(p_{w}-p_{g}\right)\left(\frac{k}{d}\right)\left(\frac{3600}{L}\right) C(G r \operatorname{Pr})^{n} \\
\frac{m_{w}}{R} & =C(G r \operatorname{Pr})^{n}
\end{aligned}
$$

where

$$
R=0.0163\left(p_{w}-p_{g}\right)\left(\frac{k}{d}\right)\left(\frac{3600}{L}\right)
$$

$P_{w}=$ Partial pressure of saturated water

$P_{g}=$ Partial pressure of glass saturated

$h_{c w}=$ heat loss coefficient by convection from water surface to glass $\left(\mathrm{W} / \mathrm{m}^{2} \mathrm{~K}\right)$

The still efficiency is defined as the ratio of heat energy used for vaporizing the water in the basin to the total Solar Intensity of radiation absorbed by the still. The daily efficiency $\eta_{d}$ is obtained by summing up the hourly condensate production m, multiplied by the latent heat of vaporization $h_{f g}$, and divided by the daily average solar radiation $I_{g}$ over the still area A.

\section{Discussion of Results}

The Solar still made up of Copper is operated from 8.00 a.m to 5.00 p.m. The measurements of the temperatures, solar radiation intensity and the production of distilled water are taken hourly to study the effect of each parameter on the still productivity without using vacuum. In this study, various operating conditions have been 
examined such as different water depths; insulation thickness, salt concentration, ambient temperature and productivity are measured hourly. The output of the solar still varies directly with the ambient temperature. The area Productivity of the solar still increases with increase in absorber area.

The productivity rate varies as time passes from the early morning until late afternoon. The hourly output is maximum in the afternoon hours when the ambient temperature is at its daily peak. The wind speed is found to be around 2 - $4 \mathrm{~m} / \mathrm{s}$. The water temperature has a direct effect on the productivity whereas the depth of water increases from 2 to 3 and $5 \mathrm{~cm}$, the daily still output decreases i.e. inversely proportional. The solar radiation is absorbed by the black painting inside the bottom of the basin and thus increases the temperature of the water In this still, the productivity increases further due to the increase in heat gain for water vaporization inside the still because copper conducts more heat compared with the still made up of Cast Iron. Due to this, the amount of distillate collected in this still is higher and hence the increase in efficiency by $80 \%$ when compared with the still made up of Cast Iron for the same basin area.

In the copper still using heat storage medium like small pebbles inside the still basin, same measurement process is repeated to find out the enhanced performance and compare them. Pebble is one of the highest solar thermal energy storage materials as it has high sensible heat. Addition of pebbles in the basin surface increases the water temperature and thereby increasing the evaporation rate. Pebble of uniform diameter $10 \mathrm{~mm}$ is used. The area Productivity of the solar still increases with increase in absorber area. This improves the evaporation rate and in turn improves the efficiency of the still to certain extent. The average daily output is found to be 3 litres/day for the basin area of $0.36 \mathrm{~m}^{2}$ based on the data of 8 days. The optimized glass cover angle is $32^{\circ}$. The efficiency is calculated as $100 \%$ higher comparable with stills being used worldwide.

The same measurement process is repeated for various parameters to find out the enhanced performance of the vacuum still and compare the performance of them. This reveals that an increase in the rate of evaporation by reducing the pressure of the still which will ensure higher rates of evaporation even at low temperatures. Furthermore, this still uses the latent heat which is released during condensation to heat up the water at lower temperature. Due to this vacuum inside the still the evaporation rate increases further and the efficiency further increases by $50 \%$ compared with the still working at atmospheric conditions. Also, it is more suitable for poor ambient conditions as the still works at low pressure and evaporation of water takes place at a low temperature.
The same measurement process is repeated for various parameters to find out the enhanced performance of the modified vacuum still with pebbles and compare the performance of them. This reveals an increase in the rate of evaporation by providing thermal storage medium which will ensure higher thermal conduction between water and the still. Due to this modification in vacuum still the evaporation rate increases further and hence the increase in efficiency by $20 \%$ in comparing with the vacuum still

\subsection{Productivity vs Time with Various Concentrations}

For a solar still made up of copper without vacuum and without gravels, Graphs are drawn for Productivity and Time for various concentrations of $0 \%, 10 \%$ and $20 \%$ and where different depths of water level of $1 \mathrm{~cm}$ and $3 \mathrm{~cm}$. It reveals an increase in the productivity for minimum depths of water level as shown in Figure 7. It also shows that the lower the salt concentrations the higher will be the productivity as shown in Figure 8.

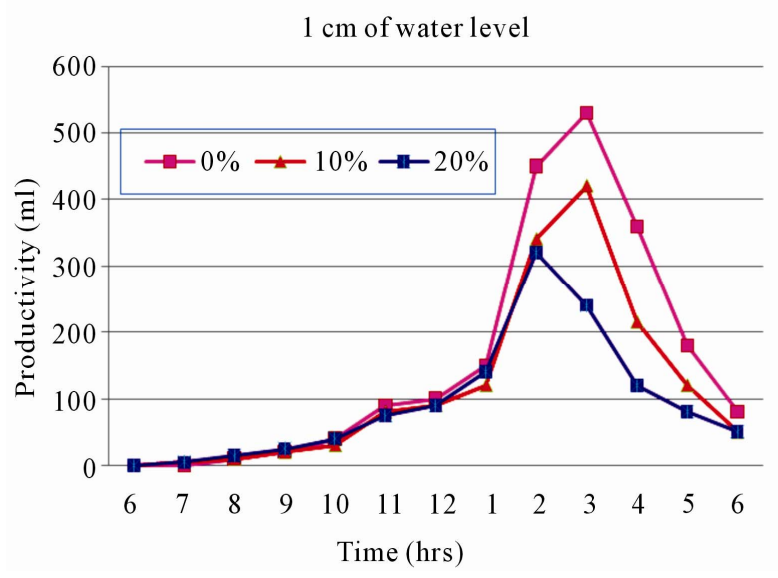

Figure 7. Productivity vs time for various concentrations.

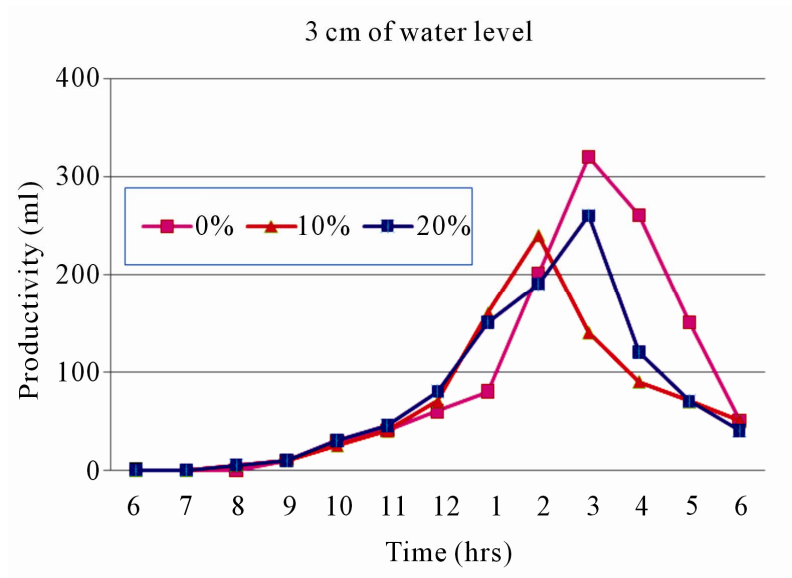

Figure 8. Productivity vs time for various concentrations. 


\subsection{Productivity vs Time with Various Levels of Water}

For a solar still made up of copper without vacuum and without gravels, Graphs are drawn for Productivity and Time for different depths of water level of $1 \mathrm{~cm}, 3 \mathrm{~cm}$ and $5 \mathrm{~cm}$ for various concentrations of $0 \%$ and $20 \%$. It reveals an increase in the productivity for the minimum depths of water level as shown in Figure 9. It also shows that the lower the salt concentrations the higher will be the productivity as shown in Figure 10.

\subsection{Productivity vs Time for with and without Vacuum}

For a solar still made up of copper with and without vacuum, Graph is drawn for Productivity and Time for the water level of $3 \mathrm{~cm}$. It reveals an increase in the productivity of the vacuum solar still due to low pressure compared with the still working at ambient conditions as shown in Figure 11.

\subsection{Productivity vs Time for Vacuum Still with and without Pebbles}

For a vacuum solar still made up of copper with and

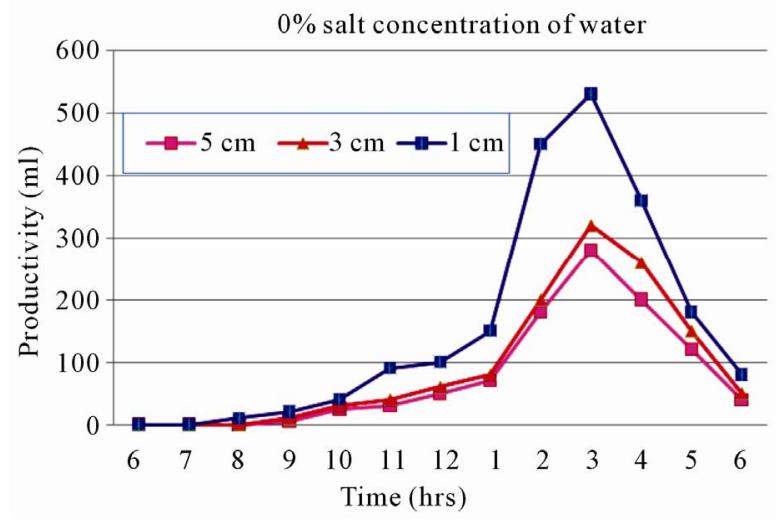

Figure 9. Productivity vs time for various levels of water.

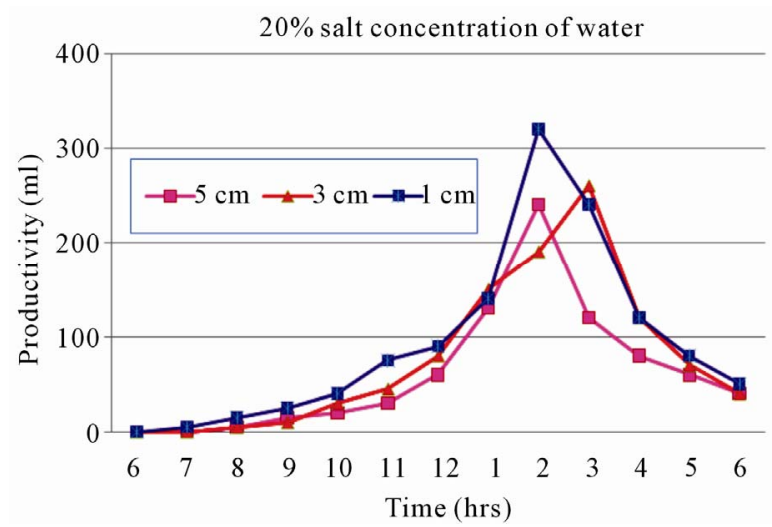

Figure 10. Productivity vs time for various levels of water. without gravels, Graph is drawn for Productivity and Time for the water level of $3 \mathrm{~cm}$ for salt concentration of $10 \%$. The productivity is higher for the vacuum still using gravels when compared with vacuum still not using gravels as shown in Figure 12.

\subsection{Cost Estimation}

The overall cost of the experimental setup is given in Table 2.

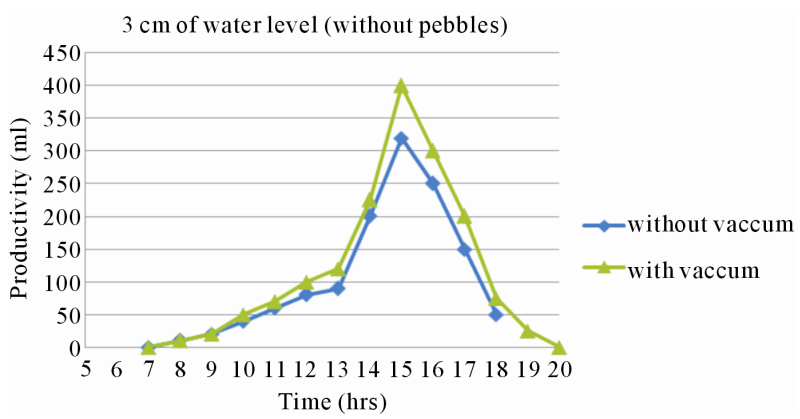

Figure 11. Productivity vs Time for with and without vacuum.

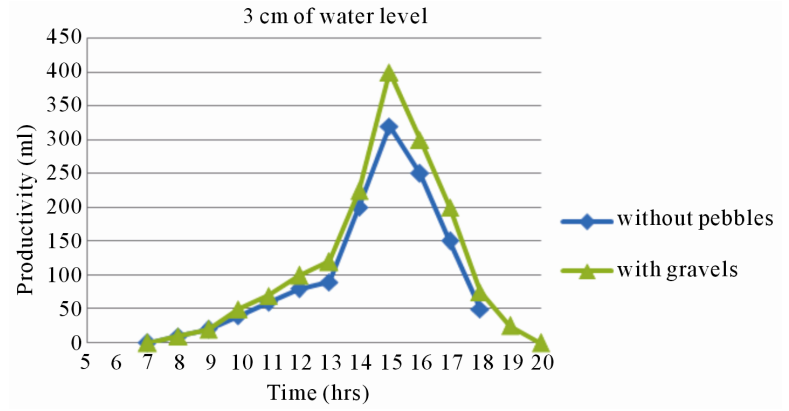

Figure 12. Productivity vs Time for Vacuum still with and without pebbles.

Table 2. Cost estimation economic analysis.

\begin{tabular}{ccc}
\hline Sl.no & Description & Amount in Rs. \\
\hline 1 & Copper sheet & 4000 \\
2 & Plywood & 1200 \\
3 & Glass & 550 \\
4 & Supply tank with accessories & 400 \\
5 & Collecting tank & 600 \\
6 & Thermocool & 150 \\
7 & Vacuum pump & 3100 \\
8 & labour charge & 500 \\
9 & Pebbles & 500 \\
& Total & Rs.11000 \\
\hline
\end{tabular}




\subsection{Economic Analysis}

The payback period of the solar still setup depends on overall cost of fabrication, maintenance cost, operating cost and cost of feed water. The overall fabrication cost is Rs.11000 (\$225). The maintenance cost, operating cost and cost of feed water are negligible. The overall cost of the project $=$ Rs.11000 (\$225). Cost of water produced per day $=$ Cost of water per litre $\times$ daily yield $=$ 8litres/dayxRs.10/lit. = Rs.80 (\$1.6)

The payback period is less than 1 Year.

\section{Conclusions}

A single basin solar still made up of copper sheet is fabricated and tested for both the conditions with and with out vacuum. The distilled water production rate of a single basin solar still can vary with the design of the solar still, absorbing materials, depth of water, salt concentration and location. The efficiency is higher for solar still made up of copper and it can be increased further by providing heat absorbing and storage materials inside the still. Addition of pebbles in the basin surface increases the water temperature and thereby increasing the evaporation rate. The Productivity of the solar still increases with increase in absorber area. The modified innovative still working under low pressure has enhanced performance in comparing with the still working at atmospheric pressure and more flexible with climatic conditions. The system will serve a family of 5 and the average water consumption is around 7.5 litres/day. The daily yield of the still is around 8 litres $/ \mathrm{day} / \mathrm{m}^{2}$. The payback period is less than 1 year. This cost-effective design is expected to provide the rural communities an efficient way to convert the brackish water in to potable water

\section{REFERENCES}

[1] O. O. Badran and M. M. Abu-khader, "Evaluating thermal Performance of a Single Slope Solar Still,” Heat And Mass Transfer, Vol. 43, No. 10, 2007, pp. 985-995. doi:10.1007/s00231-006-0180-0

[2] I. Al-Hayek and O. O. Bardan, "The Effect of Using Different Designs of Solar Stills on Water Distillation,” Desalination, Vol. 169, 2004, pp. 121-127. doi:10.1016/j.desal.2004.08.013

[3] S. Abdallah, O. Badran and M. M. Abu-Khader, "Performance Evaluation of a Modified Design of a Single-Basin Solar Still,” Desalination, Vol. 219, No. 1-3, 2008, pp. 222-230. doi:10.1016/j.desal.2007.05.015

[4] G. N. Tiwari, H. N. Singh and R. Tripathy, "Present Status of Solar Distillation,” Solar Energy, Vol. 75, No. 5, 2003, pp. 367-373. doi:10.1016/j.solener.2003.07.005

[5] K. Murugavel, K. K. S. Chockelingam and K. Srither, "Progresses in Improve the Effectiveness of the Single Basin Passive Solar Still,” Desalination, Vol. 220, No. 1-3, 2008, pp. 677-686. doi:10.1016/j.desal.2007.01.062

[6] V. Velmurugan and K. Srithar, "Performance Analysis of Solar Stills on various Factors Affecting the Productivity," Renewable Energy and Sustainable Energy, Vol. 15, No. 2, 2011, pp. 1294-1304. doi:10.1016/j.rser.2010.10.012

[7] S. A. Kalogirou, "Seawater Desalination Using Renewable Energy Sources," Progress in Energy and Combustion Science, Vol. 31, No. 3, 2005, pp. 242-281. doi:10.1016/j.pecs.2005.03.001 